\title{
Intractable restless legs syndrome: role of prolonged-release oxycodone-naloxone
}

REVIEW

\author{
This article was published in the following Dove Press journal: \\ Neuropsychiatric Disease and Treatment \\ 23 February 2016 \\ Number of times this article has been viewed
}

\author{
Stefano de Biase ${ }^{1}$ \\ Mariarosaria Valente ${ }^{1,2}$ \\ Gian Luigi Gigli',2 \\ 'Neurology Unit, Department of \\ Experimental and Clinical Medical \\ Sciences, University of Udine \\ Medical School, ${ }^{2}$ Department of \\ Neurosciences, Santa Maria della \\ Misericordia University Hospital, \\ Udine, Italy
}

Correspondence: Gian Luigi Gigli Neurology Unit, Department of Experimental and Clinical Medical Sciences, University of Udine Medical School, 15 Piazza Santa Maria, della Misercordia, Udine 33100, Italy

Tel +390432989264

Fax +390432989263

Email gigli@uniud.it

\begin{abstract}
Restless legs syndrome (RLS) is a common neurological disorder characterized by an irresistible urge to move the legs accompanied by uncomfortable sensations that occur at night or at time of rest. Pharmacological therapy should be limited to patients who suffer from clinically relevant symptoms. Chronic RLS is usually treated with either a dopamine agonist (pramipexole, ropinirole, rotigotine) or an $\alpha_{2} \delta$ calcium-channel ligand (gabapentin, gabapentin enacarbil, pregabalin). Augmentation is the main complication of long-term dopaminergic treatment, and frequently requires a reduction of current dopaminergic dose or a switch to nondopaminergic medications. Opioids as monotherapy or add-on treatment should be considered when alternative satisfactory regimens are unavailable and the severity of symptoms warrants it. In a recent Phase III trial, oxycodone-naloxone prolonged release (PR) demonstrated a significant and sustained effect on patients with severe RLS inadequately controlled by previous treatments. The adverse-event profile was consistent with the safety profile of opioids. The most frequent adverse events were fatigue, constipation, nausea, headache, hyperhidrosis, somnolence, dry mouth, and pruritus. Adverse events were usually mild or moderate in intensity. No cases of augmentation were reported. Oxycodone-naloxone PR is approved for the secondline symptomatic treatment of adults with severe to very severe idiopathic RLS after failure of dopaminergic treatment. Further studies are needed to evaluate if oxycodone-naloxone PR is equally efficacious as a first-line treatment. Moreover, long-term comparative studies between opioids, dopaminergic drugs and $\alpha_{2} \delta$ ligands are needed.
\end{abstract}

Keywords: augmentation, dopamine, oxycodone-naloxone, restless legs syndrome

\section{Introduction}

Restless legs syndrome (RLS) is a common neurological disorder characterized by an irresistible urge to move the legs accompanied by uncomfortable sensations that occur at night or at time of rest. ${ }^{1}$ According to the 2012 revised criteria, diagnosis is based on the presence of the following five criteria: 1) an urge to move the legs, usually accompanied or caused by uncomfortable and unpleasant sensations in the legs; 2) the urge to move begins or worsens during periods of rest or inactivity, such as lying or sitting; 3 ) the urge to move is partially or totally relieved by movement, such as walking or stretching, at least as long as the activity continues; 4) the urge to move is worse in the evening or at night than during the day or only occurs in the evening or night; and 5) the symptoms cannot be attributed to another medical condition (eg, leg edema, arthritis, leg cramps) or behavioral condition (eg, positional discomfort, habitual foot tapping). ${ }^{2}$ Approximately $80 \%-85 \%$ of patients with RLS have periodic and involuntary stereotyped jerks in the lower limbs, known as periodic limb movements (PLMs). ${ }^{3}$ Not surprisingly, RLS patients may complain of disruption of sleep, insomnia, and sleepiness during the day. RLS can have a serious impact on quality 
of life. Compared to the general population, RLS patients present a higher incidence of anxiety and depression. ${ }^{4}$

RLS is common in the general population, with a prevalence of 5\%-10\%. ${ }^{5}$ Approximately 2\%-3\% of adults have clinically significant symptoms, occurring at least twice a week and reported as moderately or severely distressing. ${ }^{4}$ Prevalence has been observed to rise with age, and is higher in women than in men. ${ }^{6}$

Primary and secondary forms of RLS are recognized. A large proportion of patients $(70 \%-80 \%)$ are affected by the primary form of RLS. Primary RLS usually has an earlier onset ( $<45$ years old), slower development, and a strong familial link. ${ }^{7}$ To diagnose a primary form of RLS, all the known causes of secondary forms of the disease should be excluded. ${ }^{8-13}$ Symptomatic forms of RLS may improve or disappear upon treating the underlying disorder.

The precise pathogenesis of RLS is still unknown, but dysfunctional dopaminergic modulation of neuronal excitability is generally thought to be the main underlying pathophysiological mechanism of RLS, as suggested by the positive response to dopaminergic agents in patients with RLS. ${ }^{14}$ However, there is increasing evidence that interaction with other transmitter systems, such as opioids and the $\gamma$-aminobutyric acid-ergic system, as well as iron deficiency, is crucial for the manifestation of RLS symptoms. ${ }^{15}$

Pharmacological therapy should be limited to those patients who suffer from clinically relevant symptoms. Levodopa is used as on-demand treatment in intermittent RLS, but because of its short half-life $\left(t_{1 / 2}\right)$, patients often encounter symptom rebound. ${ }^{16}$ The long-term use of levodopa often reveals tolerance and a typical complication called augmentation. Augmentation refers to the worsening of RLS-symptom severity from pretreatment levels following an initial benefit, with an earlier onset of symptoms by at least 2-4 hours, often associated with a shorter latency to RLS symptoms at rest, extension of symptoms to other body parts, and increased intensity of symptoms. ${ }^{17}$

Chronic RLS should be treated with either a nonergot dopamine agonist (pramipexole, ropinirole, rotigotine) or an $\alpha_{2} \delta$ calcium-channel ligand (gabapentin, gabapentin enacarbil, pregabalin). Short-term adverse effects due to treatment with dopamine agonists are gastrointestinal disturbances, weight gain, dizziness, sedation, and impulse-control disorders, while the main complication of long-term dopaminergic treatment is augmentation. Although less common than with levodopa, augmentation represents the main challenge in RLS treatment. The use of $\alpha_{2} \delta$ calcium-channel ligands should be considered for initial treatment of RLS patients with comorbid insomnia, anxiety, or comorbid pain. ${ }^{18}$

In refractory RLS, combination treatment should be considered for patients with symptoms that cannot be controlled with a low-dose monotherapy of either treatment class. Second agents may include a dopamine agonist for patients treated with an $\alpha_{2} \delta$ ligand or vice versa, or an opioid. ${ }^{19}$ Opioids as monotherapy or add-on treatment should be considered when alternative satisfactory regimens are unavailable and the severity of symptoms warrants it.

In a recent study, oxycodone-naloxone prolonged release (PR) was demonstrated to be efficacious in the treatment of RLS not adequately controlled with previous treatments. ${ }^{20}$ The positive response to opioid treatment suggests that the hypofunction of the endogenous opioid system might be pathogenetic in RLS. This hypothesis has been investigated in a study showing that the signs and symptoms of RLS reappear in opioid-treated patients given intravenous naloxone. ${ }^{21}$

In 2015, Targin $^{\circledR}$, a fixed combination of oxycodonenaloxone PR, received a positive European Commission decision as second-line symptomatic treatment for patients with severe to very severe idiopathic RLS after failure of dopaminergic therapy. ${ }^{22}$

The aim of this review is to describe the pharmacological, clinical, and tolerability properties of oxycodone-naloxone PR in the treatment of RLS. This is based on a literature search using the PubMed database from 1986 to 2015 . The search terms were: oxycodone-naloxone, opioid, restless legs syndrome, augmentation, and pharmacokinetics. References from identified articles and abstracts from meetings were also reviewed.

\section{Overview and pharmacological data}

Oxycodone (6-deoxy-7,8-dihydro-14-hydroxy-3-O-methyl6-oxomorphine) is a semisynthetic opioid developed from the opium derivative, thebaine. ${ }^{23}$ Oxycodone is a $\mu-, \kappa-$, and $\delta$-receptor opioid agonist whose principal therapeutic action is pain relief. It also binds to gut opioid receptors, inducing constipation. The use of oxycodone has increased in recent years, and it has replaced morphine as the most used opioid among general practitioners, as well as among hospital physicians. ${ }^{23}$ Naloxone is a semisynthetic competitive opioid antagonist that acts locally on the gut, counteracting opioid-induced constipation (OIC). It has a very high affinity for opioid receptors, and displaces opioid agonists. After systemic administration, it reverses both centrally and peripherally mediated opioid effects. ${ }^{24}$

Following oral administration, oxycodone displays high oral bioavailability $(60 \%-87 \%)$. The presence of a $\mathrm{CH}_{3}$ group at position 3 instead of an $\mathrm{OH}$ group in 
the oxycodone molecule in comparison to morphine is responsible for reduced first-pass metabolism and thus greater bioavailability. ${ }^{25}$ Oxycodone is available in immediaterelease (IR) and PR formulations. Today, oxycodone is mainly used as PR tablets for chronic pain. The IR tablets are used for acute pain or for breakthrough pain. ${ }^{26}$

The absorption profile of the PR tablet is best described using a biexponential absorption model, with a rapid initial absorption component ( $t_{1 / 2}$ of absorption 37 minutes) accounting for $38 \%$ of the available dose, followed by a slow-absorption phase ( $t_{1 / 2}$ of absorption 6.2 hours) accounting for $62 \%$ of the available dose. ${ }^{27}$

Maximum plasma concentration is reached within 1.3 hours after IR administration and 2.6 hours after administration of a PR formulation. ${ }^{26}$ The maximum plasma concentration after IR oxycodone administration is twice as high as an equivalent dose of PR oxycodone. ${ }^{27}$ The PR preparations are bioequivalent to IR preparations, allowing dosing every 12 hours. ${ }^{28}$ Food has no significant effect on the extent of absorption of oxycodone. Naloxone possesses low bioavailability after oral administration $(<3 \%)$, because of extensive first-pass hepatic metabolism. As a result, naloxone acts almost exclusively on opioid receptors in the gastrointestinal tract. ${ }^{29} \mathrm{~A}$ pharmacokinetic study demonstrated that coadministration of oxycodone PR and naloxone PR in fixed doses did not significantly affect the bioavailability of either of its constituents. ${ }^{30}$ The optimal 2:1 ratio of $\mathrm{PR}$ oxycodone:PR naloxone was demonstrated in a Phase II study, rendering effective analgesia and improvement in bowel function with good treatment tolerance in patients with severe chronic pain..$^{31,32}$

Oxycodone is approximately $45 \%$ bound to plasma proteins (mainly albumin) in a non-dose-dependent manner and is widely distributed throughout the body, with an apparent volume of distribution of approximately $2-3 \mathrm{~L} / \mathrm{kg}$. ${ }^{33}$ Oxycodone and naloxone pass into the placenta. Oxycodonenaloxone is contraindicated during pregnancy, labor, and delivery, due to impaired uterine contractility and the risk of neonatal respiratory depression. Oxycodone passes into the breast milk. It is not known whether naloxone is excreted in human milk. Since the safety of oxycodone-naloxone in infants and newborns has not been studied, it is contraindicated in nursing mothers. ${ }^{34}$

Oxycodone is mostly metabolized in the liver to noroxycodone via CYP3A4 and to a lesser extent to oxymorphone through CYP2D6; both noroxycodone and oxymorphone are subsequently converted to noroxymorphone via CYP2D6 and CYP3A4, respectively. ${ }^{35}$ The primary oxycodone metabolites (noroxycodone and oxymorphone) also display affinity for $\mu$-opioid receptors. However, noroxycodone possesses only $17 \%$ of the potency of the parent compound, while oxymorphone, in spite of high affinity for $\mu$-opioid receptors, is produced in very small amounts. ${ }^{36}$ Therefore, it is oxycodone itself that produces the analgesic effects of the opioid.

Noroxymorphone is produced in significant amounts and possesses significant affinity for opioid receptors. However, the blood-brain barrier is extremely impermeable to noroxymorphone in comparison to the parent compound, and thus its role in analgesia seems to be negligible. ${ }^{37}$

Although no clinical studies have been conducted, CYP3A4 inhibitors (eg, ketoconazole, ritonavir) may cause decreased clearance of oxycodone and increased plasma concentrations, with greater risk of toxicity. CYP3A4 inducers (eg, rifampin, carbamazepine) may cause increased clearance of the drug, which could lead to a decrease in oxycodone plasma concentrations, lack of effect, or possibly the development of an abstinence syndrome. ${ }^{34}$ Oxycodone is only partially metabolized via the hepatic CYP2D6 pathway; concomitant administration of CYP2D6 inhibitors has not been shown to be of clinical significance during oxycodone treatment. ${ }^{34}$ However, the concurrent use of CYP3A4 and CYP2D6 inhibitors can further affect oxycodone metabolism. ${ }^{38}$ A pharmacodynamic interaction of oxycodone with other drugs acting on the central nervous system, such as benzodiazepines, neuroleptics, and antidepressants, may intensify oxycodone adverse effects, especially sedation, and respiratory depression in patients that are more sensitive to opioids. ${ }^{34}$ Considering that naloxone possess low bioavailability after oral administration $(<3 \%)$, the potential for metabolism-related drug-drug interaction is low at therapeutic concentrations.

The $t_{1 / 2}$ of oxycodone is approximately 3 hours after administration with an IR solution and approximately 8 hours after PR tablets. Oxycodone is mainly excreted in urine after metabolism, with limited amounts excreted as unchanged drug. ${ }^{28}$ The main properties and pharmacokinetic parameters of oxycodone-naloxone PR are summarized in Table 1.

Oxycodone elimination is impaired with renal failure, due to an increased volume of distribution and reduced clearance. Patients with impaired renal function (creatinine clearance $<60 \mathrm{~mL} / \mathrm{min}$ ) and patients with mild-to-moderate hepatic dysfunction showed peak plasma oxycodone and noroxycodone concentrations $50 \%$ and $20 \%$ higher, respectively, than normal subjects. Oxycodone-naloxone PR should be used with caution in these populations, while it is contraindicated in patients with moderate and severe hepatic impairment (Table 2). ${ }^{28,34}$ 
Table I Main properties and pharmacokinetic parameters of oxycodone-naloxone PR

\begin{tabular}{|c|c|}
\hline Mechanism of action & $\begin{array}{l}\text { Oxycodone is a } \mu-, \kappa-\text {, and } \delta \text {-receptor opioid agonist. Naloxone is a competitive opioid antagonist that } \\
\text { acts locally on the gut, counteracting the opioid-induced constipation }\end{array}$ \\
\hline Starting dose (for RLS) & $5 \mathrm{mg} / 2.5 \mathrm{mg}$ oxycodone/naloxone BID \\
\hline Therapeutic dose (for RLS) & Up to $60 \mathrm{mg} / 30 \mathrm{mg}$ oxycodone/naloxone daily \\
\hline Dosing schedule & BID \\
\hline Absorption & $\begin{array}{l}\text { Oral administration, biexponential absorption with a rapid component ( } t_{1 / 2} \text { absorption } 37 \text { minutes) } \\
\text { accounting for } 38 \% \text { of the dose, and a slow-absorption phase ( } t_{1 / 2} \text { absorption } 6.2 \text { hours) accounting } \\
\text { for } 62 \% \text { of the available dose; oxycodone bioavailability } 60 \%-87 \% \text {; can be given without regard to meals }\end{array}$ \\
\hline Distribution & Apparent volume of distribution $2-3 \mathrm{~L} / \mathrm{kg} ; 45 \%$ bound to plasma proteins \\
\hline Metabolism & $\begin{array}{l}\text { Oxycodone is mostly metabolized in the liver to inactive noroxycodone via CYP3A4 and to a } \\
\text { lesser extent to active oxymorphone through CYP2D6; both noroxycodone and oxymorphone are } \\
\text { subsequently converted to noroxymorphone via CYP2D6 and CYP3A4, respectively }\end{array}$ \\
\hline Interactions & $\begin{array}{l}\text { CYP3A4 inhibitors may cause decreased clearance of oxycodone and an increase in its plasma } \\
\text { concentrations. CYP3A4 inducers may cause increased clearance of the drug, which could lead } \\
\text { to a decrease in oxycodone plasma concentrations, lack of effect, or possibly the development of } \\
\text { an abstinence syndrome. Other drugs acting on the CNS, such as benzodiazepines, neuroleptics, } \\
\text { and antidepressants, may intensify oxycodone adverse effects, especially sedation, and respiratory } \\
\text { depression in patients that are more sensitive to opioids }\end{array}$ \\
\hline Elimination & Mainly excreted in urine, with limited amounts of oxycodone excreted as unchanged drug; $t_{1 / 2}$ is 4.5 hours \\
\hline
\end{tabular}

Abbreviations: PR, prolonged release; RLS, restless legs syndrome; BID, bis in die (twice a day); $t_{1 / 2}$, half-life; CNS, central nervous system.

\section{Opioids and restless legs syndrome} Most patients with RLS initially respond well to dopaminergic agonists. Although initially effective, long-term dopaminergic treatment can result in loss of efficacy, difficulties with tolerability, or augmentation, necessitating a change of drug regimen. Before the study that gave the basis for the approval of oxycodone-naloxone PR as second-line symptomatic treatment for patients with severe to very severe idiopathic RLS after failure of dopaminergic therapy, opioids were used as off-label second-line treatment to treat severe RLS with no responsivity to first-line treatment. ${ }^{20,22}$ The efficacy and tolerability of opioids for the treatment of RLS have been investigated in few studies. ${ }^{39-48}$

Table 2 Oxycodone-naloxone PR in special populations

\begin{tabular}{ll}
\hline Renal impairment & $\begin{array}{l}\text { Should be used with caution in patients with } \\
\text { impaired renal function }\end{array}$ \\
Hepatic impairment & $\begin{array}{l}\text { Should be used with caution in patients with mild } \\
\text { hepatic dysfunction; contraindicated in patients } \\
\text { with moderate and severe hepatic impairment }\end{array}$ \\
Pregnancy, labor, & $\begin{array}{l}\text { Contraindicated during pregnancy, labor, and } \\
\text { delivery, due to impaired uterine contractility } \\
\text { and delivery }\end{array}$ \\
and the risk of neonatal respiratory depression \\
Sursing women & $\begin{array}{l}\text { Safety in infants and newborns has not been } \\
\text { studied; therefore, it is contraindicated in nursing } \\
\text { mothers }\end{array}$ \\
Pediatric population & $\begin{array}{l}\text { Safety and effectiveness in pediatric patients not } \\
\text { established } \\
\text { Dosage should be adjusted to the lowest dose, } \\
\text { which will achieve satisfactory symptom relief } \\
\text { with acceptable side effects }\end{array}$ \\
\hline
\end{tabular}

Abbreviation: PR, prolonged release.
In a 10-year longitudinal assessment, methadone, a longacting $\mu$-opioid agonist, has demonstrated a persistent effect. Methadone showed no augmentation with continued efficacy after the first year of treatment. Approximately $15 \%$ of the 76 patients who were started on methadone in the first year discontinued due to lack of efficacy or side effects (eg, sedation, depression, and anxiety), but none discontinued it after the first year. ${ }^{39}$ On the other hand, patients on treatment with pramipexole showed annual rates for discontinuing treatment of $9 \%$ after the first year, with annual augmentation rates of $7 \%$ compared to 0 for methadone. The medium dose of methadone at 6 months was $10 \mathrm{mg}$, and increased by $<10 \mathrm{mg}$ after $8-10$ years on this drug. ${ }^{39}$

In a retrospective case-series, of the initial 27 RLS patients in that study, 17 were still on methadone for an average duration of use of 22.9 \pm 12 months (range: 4-44 months). All of the dropouts occurred in the first 12 months of use (five for adverse events, two for lack of efficacy, and one for logistical reasons). All patients who remained on methadone reported at least a $75 \%$ reduction in symptoms, and none developed augmentation. ${ }^{40}$

In a double-blind randomized crossover trial, oxycodone or placebo was given in divided nighttime doses to eleven patients with idiopathic RLS for 2 weeks before appropriate polysomnographic studies. Leg sensations, motor restlessness, and daytime alertness were significantly improved on oxycodone compared to baseline or placebo. On an average dose of $15.9 \mathrm{mg}$ oxycodone, there was a statistically significant reduction in the number of PLMs/hour of sleep 
$(P<0.004)$ and in the number of arousals/hour of sleep $(P<0.009)$ on the drug compared to baseline or placebo. The authors concluded that oxycodone is an effective treatment for RLS and PLMs. ${ }^{41}$

Tramadol, a centrally acting synthetic opioid-like analgesic, was assessed in the management of RLS in an open-label study. ${ }^{42}$ Patients were monitored at follow-up visits at a minimum of every 3 months for a mean of 22.8 (range: 15-26) months. Tramadol dosage ranged from 50 to $150 \mathrm{mg}$ daily. The difference between pretreatment and posttreatment symptom severity was statistically significant $(P=0.0039)$. Augmentation has been reported after treatment of RLS with tramadol, while it has not been reported with other opioids. ${ }^{43,44}$

Finally, three case series reported on the successful use of morphine administered intrathecally via implantable pump for the treatment of refractory RLS. ${ }^{45-47}$ Stopping the morphine delivery resulted in unbearable RLS symptoms, suggesting that the benefit was probably not the result of a placebo effect. ${ }^{48}$

\section{Clinical efficacy of oxycodone- naloxone PR in the treatment of RLS}

The efficacy of oxycodone-naloxone PR in the treatment of severe RLS was demonstrated in a Phase III trial that investigated the efficacy and safety of oxycodone-naloxone PR in patients with severe RLS inadequately controlled by previous, mainly dopaminergic, treatments. ${ }^{20}$ This multicenter study consisted of a 12-week randomized, double-blind, placebocontrolled trial and 40-week open-label extension phase done at 55 sites in Austria, Germany, Spain, and Sweden.

Patients had symptoms for at least 6 months with an International RLS Study Group (IRLSSG) severity-rating scale sum score of at least 15 at screening (indicative of at least moderate severity). Lack of efficacy of previous drug treatment had to be a result of either intolerable side effects or insufficient efficacy, according to medical history. Patients were excluded if they had secondary RLS, sleep apnea syndrome, severe chronic obstructive pulmonary disease, narcolepsy, myoclonic epilepsy, hallucinations, or psychotic episodes. Patients were withdrawn from any current treatment for RLS before entering the study. Patients were randomly assigned to oxycodone-naloxone PR twice daily $(n=150)$ or placebo $(\mathrm{n}=154)$. The starting dose was oxycodone $5 \mathrm{mg}$, naloxone $2.5 \mathrm{mg}$ twice daily, which was increased according to investigators' opinion to a maximum of oxycodone $40 \mathrm{mg}$, naloxone $20 \mathrm{mg}$ twice daily. The primary outcome was severity of RLS according to IRLSSG severity-rating scale sum score at 12 weeks. Mean IRLSSG severity-rating

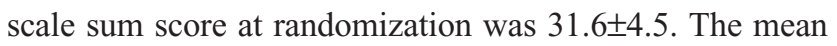
change in IRLSSG severity-rating scale sum score at 12 weeks was $-16.5 \pm 11.3$ in the oxycodone-naloxone PR group and $-9.4 \pm 10.9$ in the placebo group $(P<0.0001)$. At the end of 12 treatment weeks, more than half of all patients treated with oxycodone-naloxone PR versus less than a third taking placebo were IRLSSG severity-rating scale responders ( 75 out of 132 [57\%] vs 45 out of 144 [31\%]; $P<0.0001$ ), defined as at least $50 \%$ improvement in IRLSSG severity-rating scale score. IRLSSG severity-rating scale remitters were defined by a sum score of 0 during treatment (symptom-free) or 10 or less at the end of maintenance. During the double-blind phase, significantly more patients in the oxycodone-naloxone PR group than in the placebo group were IRLSSG severity-rating scale remitters ( $42 \%$ vs $19 \%, P<0.001)$.

Patients who completed the double-blind phase were eligible to enter the open-label extension. Of the 197 patients included in the open-label extension, 157 (80\%) completed 40 weeks of treatment. In the extension, all patients started on oxycodone $5 \mathrm{mg}$, naloxone $2.5 \mathrm{mg}$, twice a day, which was uptitrated according to investigators' opinion to a maximum of oxycodone $40 \mathrm{mg}$, naloxone $20 \mathrm{mg}$, twice a day. A beneficial effect of treatment with oxycodonenaloxone PR continued throughout the extension phase, with an IRLSSG mean sum score of $15.4 \pm 11.2$ at the start compared with $9.7 \pm 7.8$ at week 40 . At the end of the extension phase, $43 \%$ patients were classified as IRLSSG severity-rating scale remitters, and $22 \%$ of those patients had no symptoms. No cases of augmentation were reported in either phase.

The study demonstrated a significant and sustained treatment effect of oxycodone-naloxone PR. The 16.6-point reduction on the IRLSSG severity-rating scale sum score during the double-blind phase translates into a significant clinical improvement from "very severe" at start of treatment to on average "mild" or "moderate" at the end of the double-blind phase. This alleviation of symptoms also led to significant improvements in some secondary objectives, such as subjective quality of sleep and quality of life during the double-blind phase, and showed evidence of improvement in the extension phase. The data are especially convincing, because the study included patients who were refractory to other treatments. Such patients would normally be much more likely to fail an alternative treatment than patients who have not had previous treatment failure. ${ }^{49}$ Although no direct comparison can be made, the treatment effect of 
oxycodone-naloxone PR was similar or greater than that reported in previous studies of dopaminergic drugs. ${ }^{50,51}$

Oxycodone-naloxone PR is approved for the second-line symptomatic treatment of adults with severe to very severe idiopathic RLS after failure of dopaminergic treatment. ${ }^{22}$ The usual starting dose is $5 \mathrm{mg} / 2.5 \mathrm{mg}$ of oxycodone/ naloxone at 12-hour intervals. Titration on a weekly basis is recommended in case higher doses are required. The mean daily dose in the pivotal study was $20 \mathrm{mg} / 10 \mathrm{mg}$ oxycodone/ naloxone. Some patients may benefit from higher daily doses up to a maximum of $60 \mathrm{mg} / 30 \mathrm{mg}$ oxycodone/naloxone. In general, the lowest effective dose should be selected. ${ }^{34,52}$

\section{Safety and tolerability of oxycodone-naloxone PR}

Oxycodone is an opioid analgesic that has been demonstrated to provide effective analgesia in acute and chronic pain. ${ }^{26,29}$ However, the primary disadvantage associated with opioid treatment is the development of opioid-induced bowel dysfunction (OIBD), which commonly manifests as significant constipation. ${ }^{53}$ OIBD is a consequence of the action of opioids on receptors within the gastrointestinal tract, which reduce gastrointestinal motility, inhibit secretion, increase absorption, affect blood flow, and increase anal sphincter tone. ${ }^{53}$ As a result, patients can experience a range of symptoms, with constipation the most frequently reported adverse event. ${ }^{54}$ The pain and discomfort caused by OIBD can cause patients to reduce or even discontinue their opioid therapy. ${ }^{55}$

Traditional laxatives are prescribed for the prevention and treatment of OIBD, particularly for constipation. However, these possess limited efficacy and display numerous adverse effects. ${ }^{56}$ Moreover, treatment with laxatives should be limited to a short period of time. ${ }^{57}$ Prevention of OIBD is considered a more effective therapeutic strategy than merely treating the symptoms as they occur. ${ }^{57}$ The oral coadministration of opioids and opioid antagonists with limited systemic bioavailability is intended to prevent or minimize OIBD without reducing the central analgesic effects of the opioid, thanks to the lack of systemic activity. ${ }^{58}$

In a Phase III, double-blind, randomized controlled clinical trial, patients receiving a fixed combination of oxycodone-naloxone PR experienced significant improvements in OIC compared with those receiving oxycodone PR, with comparable analgesia. ${ }^{59}$

Meissner et al reported a randomized, double-blind study that assessed analgesic efficacy and impact on the OIC of oxycodone-naloxone, and identified the optimal dose ratio of oxycodone and naloxone. ${ }^{31}$ A total of 202 patients with chronic pain (most nonmalignant, $2.5 \%$ cancer-related pain) and a stable oxycodone dose $(40,60$, or $80 \mathrm{mg}$ /day) were randomized into groups that received 10, 20, and $40 \mathrm{mg}$ of naloxone daily or placebo. No loss of analgesia with naloxone PR was observed. Bowel function improved with increasing controlled-release naloxone dose. In a quadratic responsesurface model with naloxone PR and oxycodone PR doses as factors, an improvement was observed with decreasing oxycodone-naloxone ratio and appeared to plateau at the $2: 1$ ratio, with the overall effect at 2:1 being approximately $50 \%$ greater than at $4: 1$. Naloxone at doses of 20 and $40 \mathrm{mg}$ improved bowel function in comparison to placebo $(P<0.05)$. A trend toward an increase in diarrhea with the higher naloxone doses was observed, and the 2:1 oxycodone:naloxone ratio was identified as the most suitable. ${ }^{31}$

Oxycodone-naloxone PR renders similar analgesia and reverses $\mathrm{OIC}$ in comparison to oxycodone PR administered alone in patients with chronic nonmalignant pain, cancer patients with pain, and in patients with postoperative pain, and thus it improves patients' compliance and quality of life. ${ }^{60-62}$

In a study by Trenkwalder et al that evaluated the efficacy and tolerability of oxycodone-naloxone PR in the treatment of RLS, the adverse-event profile was consistent with the safety profile of opioids. ${ }^{20}$ The most frequent adverse events were fatigue, constipation, nausea, headache, hyperhidrosis, somnolence, dry mouth, and pruritus. During the doubleblind phase, adverse events related to treatment were reported in $73 \%$ of the oxycodone-naloxone PR group compared to $43 \%$ of the placebo group, while $57 \%$ of patients reported at least one adverse event related to treatment during the extension phase. The adverse events were usually mild or moderate in intensity. During the double-blind phase, 11\% of patients in the oxycodone-naloxone PR group and 5\% of placebo recipients reported severe side effects, while $9 \%$ of patients during the extension phase reported severe adverse events. Twelve ( $8 \%$ ) of 150 patients had clinically relevant constipation as an adverse event during the double-blind phase. Three patients in the oxycodone-naloxone PR group during the double-blind phase and three during the extension phase had serious treatment-related adverse events: vomiting, constipation ( $n=2)$, ileus, subileus, and acute flank pain. In the double-blind phase, a higher proportion of patients discontinued prematurely because of adverse events in the oxycodone-naloxone PR group than in the placebo group (15\% vs $7 \%$ ); during the extension phase, $9 \%$ discontinued prematurely. A follow-up visit occurred 4 weeks after the end of the open-label extension to assess symptoms of 
physical and psychological dependence (176 patients were reassessed). Drug-withdrawal symptoms occurred in one patient after 12 weeks and in two patients after 1 year of treatment. No cases of augmentation were reported during either phase. Similarly, there were no reports of opioid abuse or tolerance. ${ }^{20}$

The use of oxycodone-naloxone PR is contraindicated in patients who are hypersensitive to the active substances (oxycodone or naloxone) or to any ingredient in the formulation and in patients with acute abdominal illness, bowel obstruction, or portal circulation disturbances. ${ }^{34}$

\section{Discussion}

RLS is a common neurologic disorder, and in light of an increasing aging population, it is possible that RLS prevalence will increase in the coming years. The primary goal of RLS treatment is to reduce or eliminate symptoms and improve patient sleep and quality of life. The drugs currently available for the treatment of the disease do not always allow optimal control of symptoms, in particular in long-term treatment. Augmentation is the main complication of long-term dopaminergic treatment, and frequently requires a reduction of current dopaminergic dose or a switch to nondopaminergic medications. Studies showed a lower incidence of augmentation during long-term treatment with rotigotine than with pramipexole and ropinirole, supporting the hypothesis that the duration of action of the compound is one of the key features in the mechanism of augmentation. ${ }^{63,64} \mathrm{In}$ a recent study, the shift from IR to extended-release (ER) pramipexole was effective in reducing augmentation and improved RLS symptoms with long-term sustained results. ${ }^{64}$ It is possible that the ER versions are more efficacious and better tolerated in the long-term. However, the efficacy and tolerability of ER dopamine agonists need to be confirmed in further longer-term studies.

In clinical practice, $\alpha_{2} \delta$ calcium-channel ligands (pregabalin, gabapentin, and gabapentin enacarbil) may be used as a starting treatment in patients with concomitant problems, such as comorbid pain syndrome or insomnia. In addition, they represent a valid alternative when augmentation occurs with dopamine agonists. A recent study comparing pramipexole and pregabalin over 52 weeks has shown lower rates of augmentation for pregabalin, with similar or better long-term efficacy. ${ }^{65}$ Further longer-term comparative studies are needed, even considering ER dopamine agonists against $\alpha_{2} \delta$ ligands, to assess the main differences in efficacy and augmentation. Although a substantial number of patients are treated with a combination of dopaminergic and nondopaminergic medications in clinical practice, studies are needed to prove the efficacy of a combination treatment in RLS.

Trenkwalder et al demonstrated the efficacy and tolerability of oxycodone-naloxone PR in the long-term treatment of patients with severe RLS inadequately controlled with previous treatment. ${ }^{20}$ This study confirmed the clinical experience of good efficacy of opioids in the treatment of RLS. Oxycodone-naloxone PR is approved for the second-line symptomatic treatment of adults with severe to very severe idiopathic RLS after failure of dopaminergic treatment. ${ }^{22}$ In the study, the 16.6-point reduction on the IRLSSG severityrating scale sum score during the double-blind phase translates into a significant clinical improvement from "very severe" at the start of treatment to "mild" or "moderate" on average at the end of the double-blind phase. At the end of the extension phase, $43 \%$ of patients were considered remitters. This alleviation of symptoms also led to significant improvements in some secondary objectives, such as subjective quality of sleep and quality of life, during the double-blind phase and showed evidence of improvement in the extension phase. The treatment effect of oxycodone-naloxone PR was similar or greater than that reported in previous studies of dopaminergic drugs for moderate-to-severe RLS, although baseline severity differed in these studies. The safety profile of oxycodonenaloxone PR was as expected for opioid treatment. Severe constipation was a rare but clinically significant adverse event. Common side effects included dizziness, somnolence, headache, and fatigue, and led to treatment discontinuation in $7 \%$ of patients taking oxycodone-naloxone PR during the doubleblind phase. No cases of augmentation were reported.

Despite these considerations, opioids are still markedly underused in the treatment of RLS in situations in which alternative therapy either does not exist or is not effective. Opioids should be used at the lowest dose that relieves RLS symptoms. Opioids can be used as additional therapy to either or both dopamine agonists and $\alpha_{2} \delta$ ligands (combination therapy) or can be used alone as monotherapy. Trenkwalder et al confirmed the efficacy of oxycodonenaloxone PR in the treatment of severe RLS inadequately controlled with previous treatment. ${ }^{20}$ Further studies are needed to evaluate if oxycodone-naloxone PR is equally efficacious for first-line treatment. Moreover, long-term comparative studies between opioids, dopaminergic drugs, and $\alpha_{2} \delta$ ligands are needed.

\section{Disclosure}

The authors report no conflicts of interest in this work. 


\section{References}

1. Trenkwalder C, Paulus W, Walters AS. The restless legs syndrome. Lancet Neurol. 2005;4(8):465-475.

2. International Restless Legs Study Group. 2012 Revised IRLSSG diagnostic criteria for RLS. 2012. Available from: http://irlssg.org/ diagnostic-criteria. Accessed January 27, 2016.

3. Montplaisir J, Boucher S, Poirier G, Lavigne G, Lapierre O, Lespérance P. Clinical, polysomnographic, and genetic characteristics of restless legs syndrome: a study of 133 patients diagnosed with new standard criteria. Mov Disord. 1997;12(1):61-65.

4. Allen R, Walters A, Montplaisir J, et al. Restless legs syndrome prevalence and impact: REST general population study. Arch Intern Med. 2005;165(11):1286-1292.

5. Garcia-Borreguero D, Egatz R, Winkelmann J, Berger K. Epidemiology of restless legs syndrome: the current status. Sleep Med Rev. 2006;10(3): 153-167.

6. Ohayon MM, O'Hara R, Vitiello MV. Epidemiology of restless legs syndrome: a synthesis of the literature. Sleep Med Rev. 2012;16(4): 283-295.

7. Bassetti C, Mauerhofer D, Gugger M, Mathis J, Hess CW. Restless legs syndrome: a clinical study of 55 patients. Eur Neurol. 2001;45(2): 67-74.

8. Earley CJ, Connor JR, Beard JL, Malecki EA, Epstein DK, Allen RP. Abnormalities in CSF concentrations of ferritin and transferrin in restless legs syndrome. Neurology. 2000;54(8):1698-1700.

9. Gigli GL, Adorati M, Dolso P, et al. Restless legs syndrome in end-stage renal disease. Sleep Med. 2004;5(3):309-315.

10. Merlino G, Fratticci L, Valente M, et al. Association of restless legs syndrome in type 2 diabetes: a case-control study. Sleep. 2007;30(7): 866-871.

11. Manconi M, Ferini-Strambi L, Filippi M, et al. Multicenter case-control study on restless legs syndrome in multiple sclerosis: the REMS study. Sleep. 2008;31(7):944-952.

12. Manconi M, Govoni V, De Vito A, et al. Restless legs syndrome and pregnancy. Neurology. 2004;63(6):1065-1069.

13. O'Keeffe ST. Secondary causes of restless legs syndrome in older people. Age Ageing. 2005;34(4):349-352.

14. Hening W. The clinical neurophysiology of the restless legs syndrome and periodic limb movements. Part I: diagnosis, assessment, and characterization. Clin Neurophysiol. 2004;115(9):1965-1974.

15. Trenkwalder C, Paulus W. Restless legs syndrome: pathophysiology, clinical presentation and management. Nat Rev Neurol. 2010;6(6): 337-346.

16. Zintzaras E, Kitsios GD, Papathanasiou AA, et al. Randomized trials of dopamine agonists in restless legs syndrome: a systematic review, quality assessment, and meta-analysis. Clin Ther. 2010;32(2): 221-237.

17. García-Borreguero D, Allen RP, Kohnen R, et al. Diagnostic standards for dopaminergic augmentation of restless legs syndrome: report from a World Association of Sleep Medicine-International Restless Legs Syndrome Study Group consensus conference at the Max Planck Institute. Sleep Med. 2007;8(5):520-530.

18. Garcia-Borreguero D, Kohnen R, Silber MH, et al. The long-term treatment of restless legs syndrome/Willis-Ekbom disease: evidence-based guidelines and clinical consensus best practice guidance: a report from the International Restless Legs Syndrome Study Group. Sleep Med. 2013;14(7):675-684.

19. Ferini-Strambi L, Marelli S. Pharmacotherapy for restless legs syndrome. Expert Opin Pharmacother. 2014;15(8):1127-1238.

20. Trenkwalder C, Beneš H, Grote L, et al. Prolonged release oxycodonenaloxone for treatment of severe restless legs syndrome after failure of previous treatment: a double-blind, randomised, placebo-controlled trial with an open-label extension. Lancet Neurol. 2013;12(12): $1141-1150$.

21. Hening WA, Walters A, Kavey N, Gidro-Frank S, Cote L, Fahn S. Dyskinesias while awake and periodic movements in sleep in restless legs syndrome: treatment with opioids. Neurology. 1986;36(10):1363-1366.
22. Mundipharma. Mundipharma receives positive European Commission decision on $\operatorname{Targin}^{\circledR}$ (oxycodone/naloxone) for the treatment of restless legs syndrome [press release]. 2015. Available from: http:// www.mundipharma.com/docs/default-source/press-releases-library/ targin-rls-ec-positive.pdf?sfvrsn=0. Accessed September 25, 2015.

23. Söderberg Löfdal KC, Andersson ML, Gustafsson LL. Cytochrome P450mediated changes in oxycodone pharmacokinetics/pharmacodynamics and their clinical implications. Drugs. 2013;73(6):533-543.

24. Mueller-Lissner S. Fixed combination of oxycodone with naloxone: a new way to prevent and treat opioid-induced constipation. Adv Ther. 2010;27(9):581-590.

25. Leppert W. Role of oxycodone and oxycodone/naloxone in cancer pain management. Pharmacol Rep. 2010;62(4):578-591.

26. Kalso E. Oxycodone. J Pain Symptom Manage. 2005;29(5 Suppl): S47-S56.

27. Mandema JW, Kaiko RF, Oshlack B, Reder RF, Stanski DR. Characterization and validation of a pharmacokinetic model for controlled-release oxycodone. Br J Clin Pharmacol. 1996;42(6):747-756.

28. Lugo RA, Kern SE. The pharmacokinetics of oxycodone. J Pain Palliat Care Pharmacother. 2004;18(4):17-30.

29. Coluzzi F, Mattia C. Oxycodone: pharmacological profile and clinical data in chronic pain management. Minerva Anestesiol. 2005; 71(7-8):451-460.

30. Smith K, Hopp M, Mundin G, et al. Single- and multiple-dose pharmacokinetic evaluation of oxycodone and naloxone in an opioid agonist/ antagonist prolonged release combination in healthy adult volunteers. Clin Ther. 2008;30(11):2051-2068.

31. Meissner W, Leyendecker P, Mueller-Lissner S, et al. A randomised controlled trial with prolonged-release oral oxycodone and naloxone to prevent and reverse opioid-induced constipation. Eur J Pain. 2009; 13(1):56-64.

32. Nadstawek J, Leyendecker P, Hopp M, et al. Patient assessment of a novel therapeutic approach for the treatment of severe, chronic pain. Int J Clin Pract. 2008;62(8):1159-1167.

33. Davis MP, Varga J, Dickerson D, Walsh D, LeGrand SB, Lagman R. Normal-release and controlled-release oxycodone: pharmacokinetics, pharmacodynamics, and controversy. Support Care Cancer. 2003;11(2):84-92.

34. Purdue Pharma. Product monograph: ${ }^{\mathrm{N}}$ Targin ${ }^{\circledR}$ : oxycodone hydrochloride/naloxone hydrochloride controlled release tablets. 2014. Available from: http://www.purdue.ca/files/2014-08-05_Targin-pmmktg-eng.pdf. Accessed September 25, 2015.

35. Löwenstein O, Leyendecker P, Hopp M, et al. Combined prolonged release oxycodone and naloxone improves bowel function in patients receiving opioids for moderate-to-severe non-malignant chronic pain: a randomized controlled trial. Expert Opin Pharmacother. 2009; 10(4):531-543.

36. Leow KP, Smith MT. The antinociceptive potencies of oxycodone, noroxycodone and morphine after intracerebroventricular administration to rats. Life Sci. 1994;54(17):1229-1236.

37. Lalovic B, Kharasch E, Hoffer C, Risler L, Liu-Chen LY, Shen DD. Pharmacokinetics and pharmacodynamics of oral oxycodone in healthy human subjects: role of circulating active metabolites. Clin Pharmacol Ther. 2006;79(5):461-479.

38. Samer CF, Daali Y, Wagner M, et al. The effects of CYP2D6 and CYP3A activities on the pharmacokinetics of immediate release oxycodone. Br J Pharmacol. 2010;160(4):907-918.

39. Silver N, Allen RP, Senerth J, Earley CJ. A 10-year, longitudinal assessment of dopamine agonists and methadone in the treatment of restless legs syndrome. Sleep Med. 2011;12(5):440-444.

40. Ondo WG. Methadone for refractory restless legs syndrome. Mov Disord. 2005;20(3):345-348.

41. Walters AS, Wagner ML, Hening WA, et al. Successful treatment of the idiopathic restless legs syndrome in a randomized double-blind trial of oxycodone versus placebo. Sleep. 1993;16(4):327-332.

42. Laurma H, Markkula J. Treatment of restless legs syndrome with tramadol: an open study. J Clin Psychiatry. 1999;60(4):241-244. 
43. Vetrugno R, La Morgia C, D'Angelo R, et al. Augmentation of restless legs syndrome with long-term tramadol treatment. Mov Disord. 2007; 22(3):424-427.

44. Earley CJ, Allen RP. Restless legs syndrome augmentation associated with tramadol. Sleep Med. 2006;7(7):592-593.

45. Lindvall P, Ruuth K, Jakobsson B, Nilsson S. Intrathecal morphine as a treatment for refractory restless legs syndrome. Neurosurgery. 2008; 63(6):E1209.

46. Jakobsson B, Ruuth K. Successful treatment of restless legs syndrome with an implanted pump for intrathecal drug delivery. Acta Anaesthesiol Scand. 2002;46(1):114-117.

47. Ross DA, Narus MS, Nutt JG. Control of medically refractory restless legs syndrome with intrathecal morphine: case report. Neurosurgery. 2008;62(1):E263.

48. Hornyak M, Kaube H. Long-term treatment of a patient with severe restless legs syndrome using intrathecal morphine. Neurology. 2012; 79(24):2361-2362.

49. Walters AS. Opioids and restless legs syndrome. Lancet Neurol. 2013; 12(12):1128-1129.

50. Scholz H, Trenkwalder C, Kohnen R, Riemann D, Kriston L, Hornyak M. Dopamine agonists for restless legs syndrome. Cochrane Database Syst Rev. 2011;(3):CD006009.

51. Hornyak M, Scholz H, Kohnen R, Bengel J, Kassubek J, Trenkwalder C. What treatment works best for restless legs syndrome? Meta-analyses of dopaminergic and non-dopaminergic medications. Sleep Med Rev. 2014;18(2):153-164.

52. Frampton JE. Oxycodone/naloxone PR: a review in severe refractory restless legs syndrome. CNS Drugs. 2015;29(6):511-518.

53. Pappagallo M. Incidence, prevalence, and management of opioid bowel dysfunction. Am J Surg. 2001;182(5A Suppl):11S-18S.

54. Coluzzi F, Pappagallo M. Opioid therapy for chronic noncancer pain: practice guidelines for initiation and maintenance of therapy. Minerva Anestesiol. 2005;71(7-8):425-433.

55. Kurz A, Sessler DI. Opioid-induced bowel dysfunction: pathophysiology and potential new therapies. Drugs. 2003;63(7):649-671.
56. Larkin PJ, Sykes NP, Centeno C, et al. The management of constipation in palliative care: clinical practice recommendations. Palliat Med. 2008;22(7):796-807.

57. Leppert W. The place of oxycodone/naloxone in chronic pain management. Contemp Oncol (Pozn). 2013;17(2):128-133.

58. Sandner-Kiesling A, Leyendecker P, Hopp M, et al. Long-term efficacy and safety of combined prolonged-release oxycodone and naloxone in the management of non-cancer chronic pain. Int J Clin Pract. 2010; 64(6):763-774.

59. Simpson K, Leyendecker P, Hopp M, et al. Fixed-ratio combination oxycodone/naloxone compared with oxycodone alone for the relief of opioid-induced constipation in moderate-to-severe noncancer pain. Curr Med Res Opin. 2008;24(12):3503-3512.

60. Vondrackova D, Leyendecker P, Meissner W, et al. Analgesic efficacy and safety of oxycodone in combination with naloxone as prolonged release tablets in patients with moderate to severe chronic pain. J Pain. 2008;9(12):1144-1154.

61. Ahmedzai SH, Nauck F, Bar-Sela G, Bosse B, Leyendecker P, Hopp M. A randomized, double-blind, active-controlled, double-dummy, parallelgroup study to determine the safety and efficacy of oxycodone/naloxone prolonged-release tablets in patients with moderate/severe, chronic cancer pain. Palliat Med. 2012;26(1):50-60.

62. Kuusniemi K, Zöllner J, Sjövall S, et al. Prolonged-release oxycodone/ naloxone in postoperative pain management: from a randomized clinical trial to usual clinical practice. J Int Med Res. 2012;40(5):1775-1793.

63. García-Borreguero D, Williams AM. Dopaminergic augmentation of restless legs syndrome. Sleep Med Rev. 2010;14(5):339-346.

64. Maestri M, Fulda S, Ferini-Strambi L, et al. Polysomnographic record and successful management of augmentation in restless legs syndrome/ Willis-Ekbom disease. Sleep Med. 2014;15(5):570-575.

65. Allen RP, Chen C, Garcia-Borreguero D, et al. Comparison of pregabalin with pramipexole for restless legs syndrome. $N$ Engl J Med. 2014 370(7):621-631.
Neuropsychiatric Disease and Treatment

\section{Publish your work in this journal}

Neuropsychiatric Disease and Treatment is an international, peerreviewed journal of clinical therapeutics and pharmacology focusing on concise rapid reporting of clinical or pre-clinical studies on a range of neuropsychiatric and neurological disorders. This journal is indexed on PubMed Central, the 'PsycINFO' database and CAS,

\section{Dovepress}

and is the official journal of The International Neuropsychiatric Association (INA). The manuscript management system is completely online and includes a very quick and fair peer-review system, which is all easy to use. Visit http://www.dovepress.com/testimonials.php to read real quotes from published authors. 